\title{
Simulation of pipeline gas leakage
}

\author{
by S. Sadovnychiy ${ }^{*}$, J. Valadez ${ }^{*}$, I. Bulgakov ${ }^{*}$, A. Sadovnychyy ${ }^{* \star}$ \\ *Mexican Petroleum Institute. Mexico City, Mexico. \\ ${ }^{* *}$ National Aerospace University, Kharkiv, Ukraine.
}

\begin{abstract}
This article deals with the problem of simulation of gas leaks in pipelines and development of a prototype simulator. The prototype provides leakage simulation into water and in different kinds of soils without changing the physical properties of them. It is analyzed the behaviour of the system for different sizes of leaks and different pressures. Experimental results of the characterization of pipeline gas leakage are presented. The images of temperature anomaly were received by means of the infrared camera (Infrared camera model Palm IR 250 by Raytheon).
\end{abstract}

\section{Introduction}

In spite of the fact that oil and gas pipelines are designed, manufactured and installed to resist chemical as agents, corrosion and large stress, as time goes by, the operation in the pipeline begins to fail due to geological movements, corrosive agents, fatigue, stress and they are cause of leakage. When it happens the pollution is evident in the earth, water and environment, besides the economical losses, so it is necessary to have methods to detect this problem and consequently save trees and money. Several methods have been developed to solve this problem including the most common of volume balance and flow balance. The main advantage of these methods is the detection of the leaks in real time. The disadvantage of both methods is their low sensitivity. It is possible to detect leaks greater than $1.25-1.5 \%$ of the flow or approximately 25 litters per minute. A leak with a $0.8 \mathrm{~mm}$ diameter in a pipeline with 20 atmospheres pressure causes a loss about 1.5 litters/minute speed (less than the sensibility of the methods) which means a loss about 100 tons of oil in a lapse of 2 months (approximate time for the going up from an average pipeline depth to the surface). For this reason it is necessary to use alternative methods for leaking detection.

The usage of infrared technology for leaking detection is a method which allows to find out small outflow on early stages.

\section{Methodology}

The temperature anomalies are formed by the following causes [1]:

The first principle of temperature anomalies detection is based on the supposed theory that according to Joule-Thomson effect, the part of liquid that flow out under pressure from a crack is converted to a gas phase and lower temperature of the environment (surface over the pipeline). Thus, around the leaking place (over the land surface or in the waters) the local sites will make up with a least temperature that can be registered by the IR equipment. Visually, such leaks are impossible to be detected. A similar mechanism is presented in the gas pipes.

The second principle. There is an IR camera that can produce images at two bands: one in the absorption band of ethane and the other where ethane is nearly transparent. The image looks through a natural gas plume to the ground. Transmittance 
in air is 1.0, and transmittance through the gas plume is 0.95 . In this scenario, the radiance passing through the ethane plume will be cooler.

The temperature of the soil in a given nature, undisturbed by human hand, it is determined on the one hand by insulations and on the other by heat flowing from the interior of the Earth towards its surface. Insulation has a double period, a daily and a yearly one. The internal heat flow, due primarily to radioactive decay is constant in a fair approximation at any geographical location. Its magnitude is less by about two orders of magnitude in depth range of 1-2 meters.

Daily fluctuation is almost imperceptible at $1 \mathrm{~m}$ depth, being less than $0.1{ }^{\circ} \mathrm{C}$ in most of the cases. The yearly wave will cause measurable temperature changes to depth of 25-30 m, depending on the thermal properties of the ground [2]. Hence, the influence of these factors on the leak simulation can be not considered.

The leak types are determined by the environment in which the product is injected. The leaks can be classified as opened and closed. In the first case a product (gas, petroleum, and gasoline) leaves directly in the atmosphere. In the second case the product leaves in a ground, snow or water on various depths.

The basic leak parameter is its intensity. Leak intensity is defined by the product quantity which outflows from the pipeline aperture in time unit. Intensity depends on a difference of pressure in the pipeline and an environment, and from the aperture area too.

Usually, the simulation of close leaks is carried out as follows [3]. The hole is excavated out in a ground. On the hole bottom the open end of the pipe that is connected with a pipeline is located. Then the hole is buried by the ground taken out from it. A variety of a simulation scenarios is achieved by a variation of hole depths and change of a by-pass pipe diameter.

This method has some disadvantages. Firstly, at hole caving and subsequently burying them, the structure of a ground, its density, humidity etc. is broken. Thus, conditions of modelling differ from real. In the second, for change of leak intensity it is necessary each time to pull out a by-pass pipe and to replace it by pipe with other diameter. In the third, the bleeding of gas occurs from working pipeline and it is necessary to place the experiment area nearly with it. In summary, for the same reason, there is no opportunity to change the leak pressure i.e. to vary intensity without the change of the leak diameter.

\section{Theoretical model}

The flow temperature of oil injected into a pipeline will usually differ from soil temperature, the soil being mostly cooler than the oil. Part of the potential energy of oil flowing in the pipeline, transformed into heat, will warm the oil. A relative increase in temperature will result also from the solid components separating out of the oil which is an exothermic process. Oil temperature is reduced, on the other hand, by the transfer of heat from the pipeline into the lower-temperature environment.

The parameter, which characterizes a heat transfer from the pipeline to the earth surface, is named as a heat-transfer coefficient. In pipeline practice, pipes are usually buried in the ground, laid in a ditch dug for the purpose, and covered with backfill. Assuming the soil to be homogeneous as to head conductivity, the head flow pattern for steady-state flow is described by the stream-line and the orthogonal set of isotherms.

The increase of temperature of a ground surface above the pipeline is determined by Eq. (1) [4]: 


$$
\Delta T_{R} \approx \frac{\varepsilon \cdot\left(T_{n}-T_{0}\right) \cdot C}{\alpha \sqrt{r_{a t} / \pi} \pi\left[\frac{S}{\lambda_{a t}}+\frac{1}{\lambda_{t r}} \cdot \ln \left(\frac{h^{*}+C}{r_{a t}}\right)\right] \cdot\left(-\lambda_{t r} / \alpha\right)^{3 / 2}}
$$

where: $\varepsilon$ - thermal radiation coefficient; $\mathrm{T}_{\mathrm{n}}$ - pipe wall temperature, $(\mathrm{K}) ; \mathrm{T}_{\circ}$ - land temperature in the depth of the pipe, $(\mathrm{K}) ; \alpha$ - thermal response coefficient of the land surface, $\left(\mathrm{Wt} / \mathrm{m}^{2} \mathrm{~K}\right) ; \mathrm{r}$ - external radius of the pipe without thermal insulation, $(\mathrm{m}) ; r_{\mathrm{at}}$ external radius of the pipe with thermal insulation, $(\mathrm{m})$; $\mathrm{S}$ - thermal insulation thickness, (m); $\lambda_{t r}$ - thermal conductivity of the land $(\mathrm{Wt} / \mathrm{m} \mathrm{K}) ; \lambda_{a t}$ - thermal conductivity of insulation, $(\mathrm{Wt} / \mathrm{m} \mathrm{K}) ; \mathrm{h}$ - distance between pipeline axis and surface, $(\mathrm{m})$; $C=\sqrt{h^{* 2}-r_{a t}^{2}} ; h^{*}=h+\frac{\lambda t r}{\alpha}$.

It is possible to examine a gas or petroleum leak as some under ground virtual channel with small caliber. The temperature is lowered with the increase of distance from a leak place. If to investigate the offered leak model, it is possible to show that the distribution of temperatures on depth will be submitted as on figure 1 (for parameters $\mathrm{h}=1.5 \mathrm{~m}$, $\mathrm{T}_{\mathrm{n}}-\mathrm{T}_{0}=8^{\circ} \mathrm{K}$, thermal conductivity of the land $\lambda_{\mathrm{tr}}=1.5 \mathrm{~W} / \mathrm{mK}, \alpha=15 \mathrm{~W} / \mathrm{m}^{2} \mathrm{~K}$, the isolation is away, $r_{k}=0.03 \mathrm{~m}$ ) [4]. On figure 3 , lines $1,2,3,4,5$ and 6 correspond to the temperature on depths $0.5 ; 0.4 ; 0.3 ; 0.2 ; 0.1$ and 0 metres accordingly.

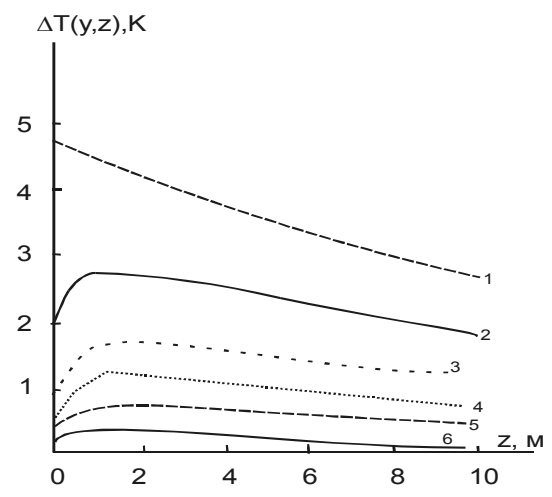

Fig. 1. Temperature distribution.

\section{Leak simulator}

The gas leakage simulator and some main considerations to design and integrate the system are described in this section.

In order to have a control of the system pressure there are three tanks (1000 Its. each one) to store enough gas/air, they are connected together and consequently at the same system pressure which is regulated by a valve. To inject the gas/air from the tanks to the analysis area it is used a high pressure hose and a special mechanical device which has been developed. This device consists of a thin tube $(19.05 \mathrm{~mm}$ of outside diameter) which is nailed with an inclination about 30 degrees into the area to be analyzed. There is a thread at the end of the tube just before the tip which avoids 
leakage of the injected gas/air through the annular space between the soil and the tube. Additionally the device has a special interchangeable tip to vary the diameter of the leak, and finally the tip has a cover to avoid the land blocks the hole of the tube during the nailing process. With these considerations, it is assured not to change the physical properties of the soil that could affect the results of the experiments. There are also manometers at the tanks output and just before the tube nailed in the soils, so the changes of the system pressure can be measured in real time. The corresponding tip of the tube can be changed to vary the diameter of the leak, thus the flow of the leak can be manipulated changing this tip and the pressure of the system.

\section{Simulation test}

The prototype has been tested in several weather conditions, besides the temperature of the soil or/and water are taken (using a IR thermometer model IR 500 by Infrared, Inc.) before and during the experiment, two materials as marks are exposed at the same atmospheric conditions to have reference temperatures. In this casel were a sheet of iron and a piece of wood. The difference of temperatures is due to the capacity of the each material to consume and conserve heat, so if the materials are different consequently they get different temperatures. The images which are gotten by the infrared camera (Infrared camera model Palm IR 250 by Raytheon) can be calibrated using these temperatures of the marks to get a better result in the temperature analysis of the system.

The infrared camera was located approximately $17 \mathrm{~m}$. above the area to be analyzed. The experiment starts when the valve is opened thus the gas/air is injected into the soil or water, besides getting the images with the infrared camera, the pressure of the systems, the temperatures of the analysis area and marks are monitored.

Although it's better a vertical view from the camera to the analyzed area, it is possible to use the camera with a little inclination without lose many details of the analyzed area.

Several experiments that using the leakage gas simulator described in previous section were made. The pressures used to simulate were from $1 \mathrm{Kg} / \mathrm{cm}^{2}$, the diameter of the leakage was from $1 \mathrm{~mm}$ to $6 \mathrm{~mm}$. There are important factors which contribute the changes of temperature in the soil during the leakage, such the sun, the meteorological conditions, the pipeline temperature, the thermal radiation coefficient, thermal conductivity of the land or water, the distance from the pipeline to the surface, as they were described in the theoretical model in section 3.

Although the infrared camera has a resolution of $0.1{ }^{\circ} \mathrm{C}$, this difference of temperature in the soil or water is not enough to suggest that it could be a leak. It's considered that the soil could have different temperature if this is not homogeneous, or if there are things that don't permit the view of the IR camera mounted in an aircraft for instance to the area to be analyzed.

It has been paid special attention in the period of time when the leakage simulator started until the changes of temperature of the soil was visible by the infrared camera.

The experiments were made in a soil with $0.7 \mathrm{~m}$ of pasture approximately, and the lands were wet in this kind of soils generally, so the temperature was less in this case than the surface during the day in spring or summer for example. In the case of the leakage simulation into water, the reflection of the sun light must produce false alarms.

The experiment 1 and 2 were in soil and the experiment 3 was made into water. 


\section{http://dx.doi.org/10.21611/qirt.2004.013}

\subsection{Experiment 1}

In the figure 2 can be observed the place of the leak before this started, and in the figure 3 is showed the same place after $10 \mathrm{~min}$ of leaking, there is exist a clear difference between the two images and just with $10 \mathrm{~min}$. of leak, the temperatures difference can be seen easily. A mark of $0.30 \mathrm{~m}$. diameter approximately appears in the figure 3 , the pressure of the leak is only $6 \mathrm{~kg} / \mathrm{cm}^{2}$, the diameter of the leak is $2 \mathrm{~mm}$ and the depth is $0.30 \mathrm{~m}$. All atmospheric conditions like sun, air, humidity, etc. affect the results directly. In spite of the fact that the marks depend strongly of atmospheric conditions, they can be used to get better results. This is monitoring the contaminated area in the better conditions, for instance without rain or sun, and is preferable in the morning before the sun goes out or in the night.

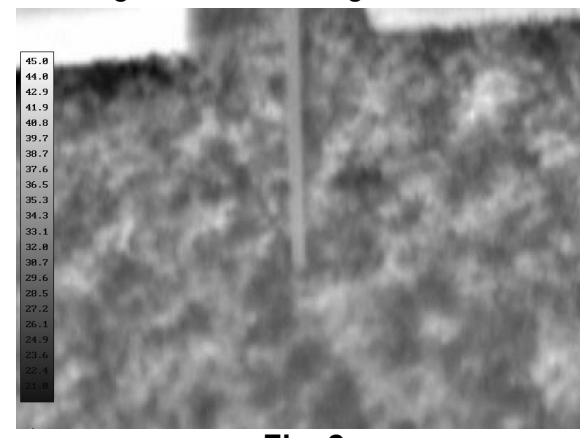

Fig. 2.

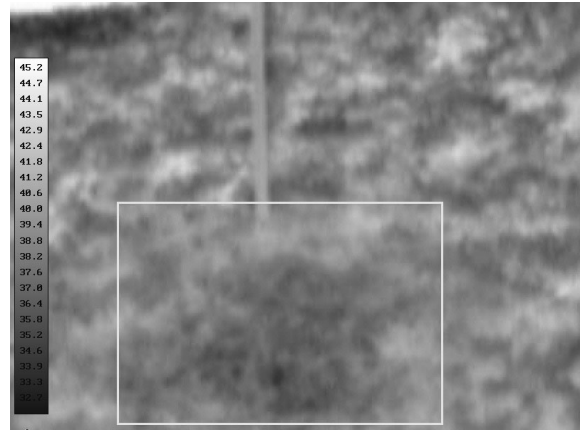

Fig. 3.

\subsection{Experiment 2}

In figures 4 and 5 are showed the same experiment that the described above, with the same parameters but in this case the injected pressure was $3 \mathrm{~kg} / \mathrm{cm}^{2}$. It can be seen almost the same intensity of the mark but with a smaller diameter $(0.13 \mathrm{~m}$ approximately), this means that the pressure affects strongly to the diameter of the mark.

The diameter of the mark in the soil varies mainly according to the pressure, the diameter of the leak and the resistivity of the soil. It means that the gas/air tries to follow the way with least resistivity, so if it is supposed homogeneous soils in the most of the cases, the mark will appear almost above of the leak and if the pressure is high, the mark is bigger in diameter, and if the diameter of the leak is bigger then the mark is clearer. This depends of the different kind of soils.

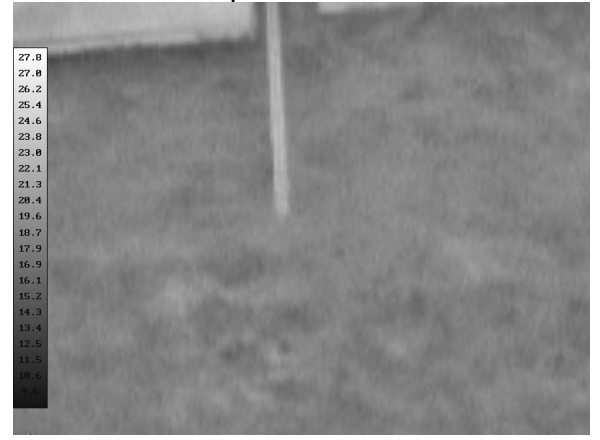

Fig. 4.

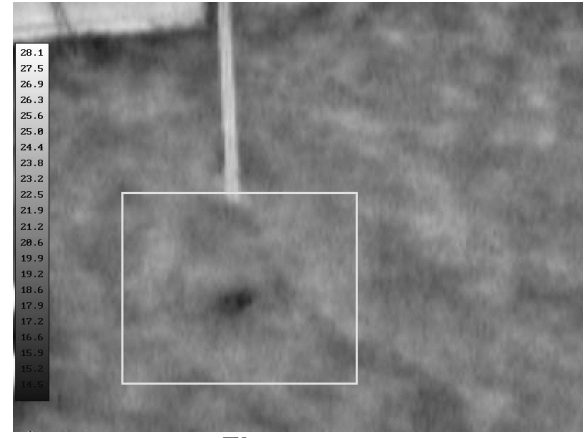

Fig. 5. 
The results are summarized in the tables 1 and 2 .

Table 1. Temperature analysis of the simulated gas leakage in experiment 1.

\begin{tabular}{|c|c|c|c|c|c|c|}
\hline Time & Pressure $\left[\mathrm{kg}^{2} / \mathrm{cm}^{2}\right]$ & $\mathrm{T}_{\text {iron }}\left[{ }^{\circ} \mathrm{C}\right]$ & $\mathrm{T}_{\text {wood }}\left[{ }^{\circ} \mathrm{C}\right]$ & $\mathrm{T}_{\text {soil }}\left[{ }^{\circ} \mathrm{C}\right]$ & $\mathrm{T}_{\text {mark }}\left[{ }^{\circ} \mathrm{C}\right]$ & $\mathrm{T}_{\text {gas/air }}\left[{ }^{0} \mathrm{C}\right]$ \\
\hline Start & 6.1 & 35 & 34 & 26 & 26 & 24 \\
\hline 5 min & 6.0 & 34 & 34 & 26 & 25 & 24 \\
\hline 30 min & 5.8 & 51 & 45 & 35 & 32 & 24 \\
\hline 1 hour & 5.7 & 53 & 47 & 36 & 28 & 24 \\
\hline 2 hour & 6.0 & 53 & 45 & 31 & 21 & 24 \\
\hline
\end{tabular}

Table 2. Temperature analysis of the simulated gas leakage in experiment 2.

\begin{tabular}{|c|c|c|c|c|c|c|}
\hline Time & Pressure $\left[\mathrm{kg}^{2} / \mathrm{cm}^{2}\right]$ & $\mathrm{T}_{\text {iron }}\left[{ }^{\circ} \mathrm{C}\right]$ & $\mathrm{T}_{\text {wood }}\left[{ }^{\circ} \mathrm{C}\right]$ & $\mathrm{T}_{\text {soil }}\left[{ }^{\circ} \mathrm{C}\right]$ & $\mathrm{T}_{\text {mark }}\left[{ }^{\circ} \mathrm{C}\right]$ & $\left.\mathrm{T}_{\text {gas/air }}{ }^{\circ} \mathrm{C}\right]$ \\
\hline Start & 3.1 & 30 & 28 & 25 & 23 & 23 \\
\hline $10 \mathrm{~min}$ & 3.0 & 49 & 36 & 21 & 19 & 24 \\
\hline $30 \mathrm{~min}$ & 3.2 & 48 & 37 & 23 & 20 & 24 \\
\hline 1 hour & 3.0 & 50 & 40 & 31 & 22 & 24 \\
\hline
\end{tabular}

\subsection{Experiment 3}

Figures 6 and 7 show the leakage simulation into water, using a tank $(3.1 \mathrm{~m}$ diameter) and the simulator described in section 4 . The leak depth is about $0.7 \mathrm{~m}$, the diameter of the leak is only $1 \mathrm{~mm}$ diameter, the pressure and temperature of the injected air is $7.5 \mathrm{~kg} / \mathrm{cm}^{2}$ and $35^{\circ} \mathrm{C}$ respectively.

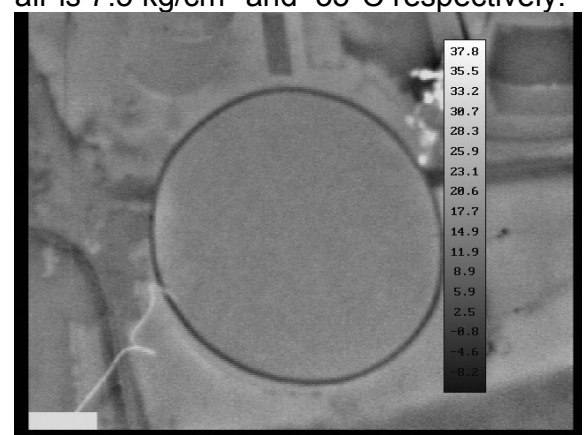

Fig. 6.

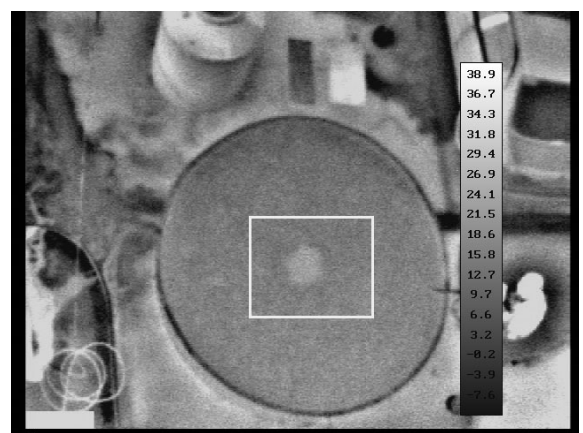

Fig. 7.

It can be seen clearly in figure 7 when the leak has just started that appears a mark in the water surface about $0.4 \mathrm{~m}$ diameter, and according to the scale temperature this mark has a difference approximately about $9^{\circ} \mathrm{C}$ from the rest of the water surface.

\section{REFERENCE}

[1] Sadovnychiy S.; Ramirez T.; Theoretical Base for Pipeline Leakage Detection by Means of IR Camera, Thermosence XXIII Conference-2001 Proceeding, Editor SPIE International Society for Optical Engineering. P, 177 - 183. Orlando, (2001)

[2] Szilas A.P. Production and transportation of oil and gas. Elsevier pub. (1975)

[3] Aleev R.M.; Ovsiannicov V.A.; Chepurskiy V.N. On Board Infrared Equipment for Petroleum Pipes Inspection, Moscow, (1995)

[4] Geoecological inspection of oil industrial enterprises. Edited by Shevnin V.A. and Modin I.N., RUSO, Moscow, (1999) 